\title{
Empty Sella Is a Sign of Symptomatic Lateral Sinus Stenosis and Not Intracranial Hypertension
}

\author{
(D) A. Zetchi, (1DM.-A. Labeyrie, (DE. Nicolini, (D) M. Fantoni, (D) M. Eliezer, and (DE. Houdart
}

\begin{abstract}
BACKGROUND AND PURPOSE: Empty sella has been reported in patients with idiopathic intracranial hypertension and is thought to be a sign of elevation of intracranial pressure. However, it can also be found in patients with lateral sinus stenosis presenting with isolated pulsatile tinnitus without signs of intracranial hypertension. We hypothesized that the volume of the sella turcica would be similar in both groups of patients undergoing stent placement for lateral sinus stenosis.
\end{abstract}

MATERIALS AND METHODS: Consecutive patients with idiopathic intracranial hypertension or isolated venous pulsatile tinnitus and undergoing lateral sinus stent placement from January 2012 to December 2017 were included. The primary outcome was the estimated volume of the sella turcica based on preoperative CTA measurements. The ratio of the pituitary gland height/sellar height was calculated on preoperative MR imaging. Sellar volumes were compared among the 3 groups: pulsatile tinnitus, idiopathic intracranial hypertension, and a control group, matched by age and sex.

RESULTS: Eighty-eight patients underwent lateral sinus stent placement. The median age was 37 years, and $94 \%$ were women. No difference in age, sex, or body mass index was found among the groups. Patients undergoing venous stent placement had significantly higher sellar volumes than the control group $(P<0.001)$. There was no difference in the sellar volumes $(P=.63)$ or gland/ sellar height ratios $(P=.25)$ between the pulsatile tinnitus and idiopathic intracranial hypertension groups.

CONCLUSIONS: Empty sella is found in 2 differing groups of patients undergoing lateral sinus stent placement, suggesting that it is a radiologic sign of symptomatic hemodynamic lateral sinus stenosis rather than elevated intracranial pressure.

ABBREVIATIONS: $\mathrm{BMI}=$ body mass index; $\mathrm{GH} / \mathrm{SH}=$ ratio of pituitary gland height/sellar height; $\mathrm{IIH}=$ idiopathic intracranial hypertension; $I \mathrm{PT}=$ isolated venous pulsatile tinnitus

$\mathbf{E}^{\mathrm{n}}$ mpty sella is defined as a widening of the sella turcica associated with an intrasellar arachnoidocele. Secondary forms can follow a pituitary operation or trauma. ${ }^{1}$ Empty sella is a radiologic sign that has been described in patients with idiopathic intracranial hypertension $(\mathrm{IIH})^{2-5}$ and is often reported as a chronic consequence of the elevation of intracranial pressure. ${ }^{6,7}$ $\mathrm{IIH}$ is associated with a large number of cases with lateral sinus stenosis, ${ }^{8,9}$ which is increasingly being treated by lateral sinus stent placement. ${ }^{10-12}$ Pulsatile tinnitus may constitute 1 mode of presentation of IIH. ${ }^{13}$ Lateral sinus stenosis may also be revealed by pulsatile tinnitus without evidence of intracranial hypertension. ${ }^{14-17}$ When pulsatile tinnitus is disabling, stent placement for

Received April 11, 2019; accepted after revision August 1.

From the Service de Neuroradiologie du Pr Houdart, Hôpital Lariboisière, Paris, France.

Please address correspondence to Akli Zetchi, MD, Service de Neuroradiologie du Pr Houdart, Hôpital Lariboisière, APHP, 2, rue Ambroise Paré, Paris 75010, France; e-mail: akli.zetchi@gmail.com

http://dx.doi.org/10.3174/ajnr.A6210 lateral sinus stenosis may be efficient for suppressing it. ${ }^{18-20} \mathrm{We}$ therefore hypothesized that an empty sella is a consequence not of the elevation of the intracranial pressure but of the venous sinus stenosis. This stenosis, when symptomatic, may present in the form of either IIH or isolated venous pulsatile tinnitus (IPT). In the current study, we measured and compared the volumes of the sella turcica in patients with sinus stenosis revealed by IIH or IPT and treated by sinus stent placement. We compared the results of these 2 groups with those obtained in a control group of subjects free of venous sinus stenosis.

\section{MATERIALS AND METHODS Study Population}

Consecutive patients undergoing lateral sinus stent placement from January 2012 to December 2017 were screened using a local data base and by cross-referencing it with the data base of the neuroradiology department archives. Patients with the combination of IIH or IPT and radiologic evidence of lateral venous sinus stenosis were included. IPT was defined as a pulsatile tinnitus in 


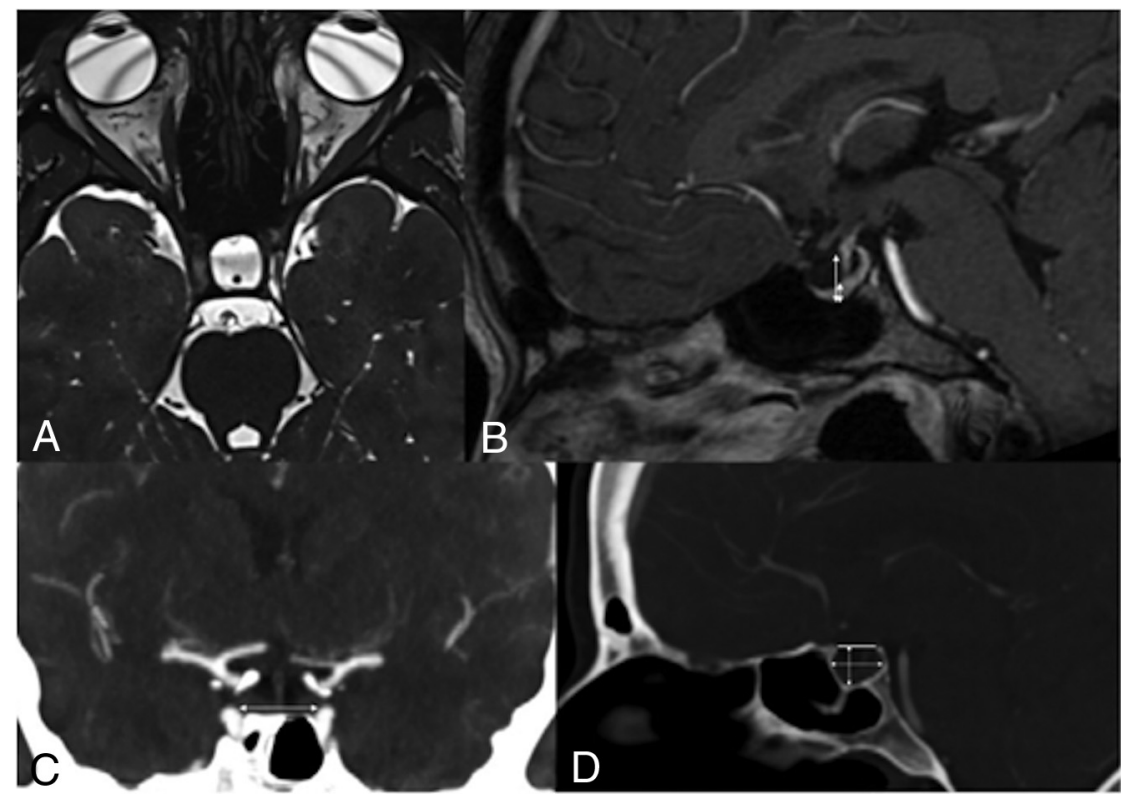

FIG 1. A 47-year-old female patient who presented with right-sided disabling pulsatile tinnitus disappearing on compression of the right jugular vein. MR imaging with an axial CISS sequence (A) shows enlargement and CSF infiltration of the sella turcica. Sagittal T7-weighted MR imaging with gadolinium shows flattening of the pituitary gland $(B)$. Ratios of pituitary gland height/sellar height were calculated on sagittal reconstruction of a 3D gadolinium-enhanced T7 MRI sequence using the cut showing the thickest section of pituitary gland $(B)$. Sellar volumes were estimated on the basis of dimensions measured on a preoperative CTA. The laterolateral dimension of the sella was measured on the coronal MPR of the preoperative CTA as shown in C using the longest measurement between the medial walls of the cavernous segments of the internal carotid arteries (white arrow). The sellar height and anterior-posterior diameter were measured on the 3D-MPR in the midsagittal plane as shown in D. Height was the longest measurement intersecting a line joining the tuberculum and dorsum sellae and the lowest point in the sella. The anterior-posterior measurement was defined as the longest measure on the midsagittal plane (white arrows).

relation to a lateral sinus stenosis (ie, disappearing after stent placement of the stenosis) and without clinical signs of IIH. Patients with a current or past history of spontaneous or traumatic CSF leak, sellar pathology including those who underwent transphenoidal surgery, and those who presented with another potential etiology for their pulsatile tinnitus were excluded. Patients with no available preoperative and/or postoperative imaging were also excluded. Patients in whom the venous stent placement procedure failed or was not completed were also excluded. This study was approved by the institutional review board.

\section{Data Collection}

Patients' baseline demographic data and body mass index (BMI) were collected. All imaging was independently reviewed by 2 authors, one experienced neurointerventionalist (A.Z.) and a fellow in interventional neuroradiology (E.N.). Trans-stenotic gradients derived from venous manometry and the type of stenosis were also recorded. The primary outcome was defined as the estimated volume of the sella turcica based on measurements on a preoperative CTA. Maximal anterior-posterior $(A P)$ and height $(H)$ measurements were obtained on midsagittal 3DMPR reconstruction. Maximal laterolateral $(L)$ measurements were obtained on coronal 3D-MPR reconstruction (Fig 1). The volume of the sella turcica $(V)$ was estimated on the basis of the formula for an ellipsoid volume:

$$
V=\frac{A P \times L \times H}{1,91} .
$$

The ratio of the pituitary gland height/sellar height $(\mathrm{GH} / \mathrm{SH})$ was also calculated on the basis of preoperative 3D gadolinium-enhanced T1weighted MR imaging with sagittal reconstruction (Fig 1). The section showing the thickest pituitary gland was chosen.

\section{Diagnosis and Treatment}

Most patients were assessed and treated by our senior author (E.H.). Patients presenting with symptoms of IIH according to the modified Dandy criteria $^{21}$ were studied by lumbar puncture with opening pressure measurements and an ophthalmologic assessment. Lumbar puncture was not performed on patients with IPT when they were free of any clinical sign of IIH, including headache, papilledema, or cranial nerve VI palsy. Patients with IIH or IPT were studied with

CTA and cerebral MR imaging, including 3D-TOF, T1-weighted with gadolinium, and MRV sequences.

CT angiography was performed on Somatom Sensation 64 CT scanner (Siemens, Erlangen, Germany) using the following parameters: section thickness $=0.75 \mathrm{~mm} ; 80 \mathrm{mAs}$; and $120 \mathrm{kV}$ (peak) per section.

MR imaging examinations were performed on a $3 \mathrm{~T}$ scanner (Magnetom Skyra; Siemens) with a 64-channel head-neck-spine coil after contrast media administration $(0.2 \mathrm{~mL} / \mathrm{kg}$ ) (gadoterate megluimine, Dotarem; Guerbet, Aulnay-sous-Bois, France). We performed the $3 \mathrm{D}$-TOF sequence with the following parameters: FOV $=200 \times 200 \mathrm{~mm}, \mathrm{TR}=21 \mathrm{~ms}, \mathrm{TE}=3.69 \mathrm{~ms}, 384 \times 278$ $\mathrm{mm}, \mathrm{NEX}=1$, and scan time $=4$ minutes 40 seconds. We performed a 3D-T1 MPRAGE sequence with the following parameters: $\mathrm{FOV}=270 \times 270 \mathrm{~mm}, \mathrm{TR}=2000 \mathrm{~ms}, \mathrm{TE}=2.68 \mathrm{~ms}, 320 \times$ $288 \mathrm{~mm}, \mathrm{NEX}=2$, generalized autocalibrating partially parallel acquisition $=2$, and scan time $=4$ minutes 4 seconds. We also performed a 3D-T2 CISS sequence with the following parameters: $\mathrm{FOV}=145 \times 145 \mathrm{~mm}, \mathrm{TR}=6.6 \mathrm{~ms}, \mathrm{TE}=3.1 \mathrm{~ms}, 320 \times 320$ $\mathrm{mm}$, flip angle $=57^{\circ}, \mathrm{NEX}=1$, and scan time $=4$ minutes 30 seconds.

When stent placement of the lateral stenosis was considered, a catheter cerebral angiography was performed with the patient 
under local anesthesia, and pressure measurements were performed in the lateral sinus proximal and distal to the stenosis. Trans-stenotic gradient measurements were obtained by microcatheter pressure transducer manometry and Verrata fractional flow reserve piezoelectric 0.014-inch microguidewire (Philips Volcano, San Diego, California) velocity and pressure measurements. The gradient was considered high if it was equal or superior to $8 \mathrm{~mm} \mathrm{Hg}$.

Patients with confirmed IIH were first treated medically with acetazolamide and lumbar puncture. In case of refractory or recurrent symptoms after a minimum of 4 months of medical treatment, lateral sinus stent placement was proposed. We selected the dominant sinus in IIH. For IPT, disability was assessed on a visual analog scale from 0 to 10 . Stent placement was proposed when the score reached or exceeded 5. In this group, venous stent placement was performed on the symptomatic side. Our technique for venous sinus stent placement has been previously described. ${ }^{22}$

\section{Data Analysis}

Sellar volumes were compared among 3 groups: patients with IPT, patients with confirmed IIH, and a control group. The sample of control subjects comprised patients with normal findings on CTA after presentation to our emergency department, matched by age and sex. Control subjects were selected if they had no past or present intracranial pathology, no history of pulsatile tinnitus, no clinical sign of $\mathrm{IIH}$, and no radiologic evidence of cerebral venous sinus stenosis. Kruskal-Wallis, ANOVA, and Dunn 2-tailed tests were used. A $P$ value $<.05$ was considered

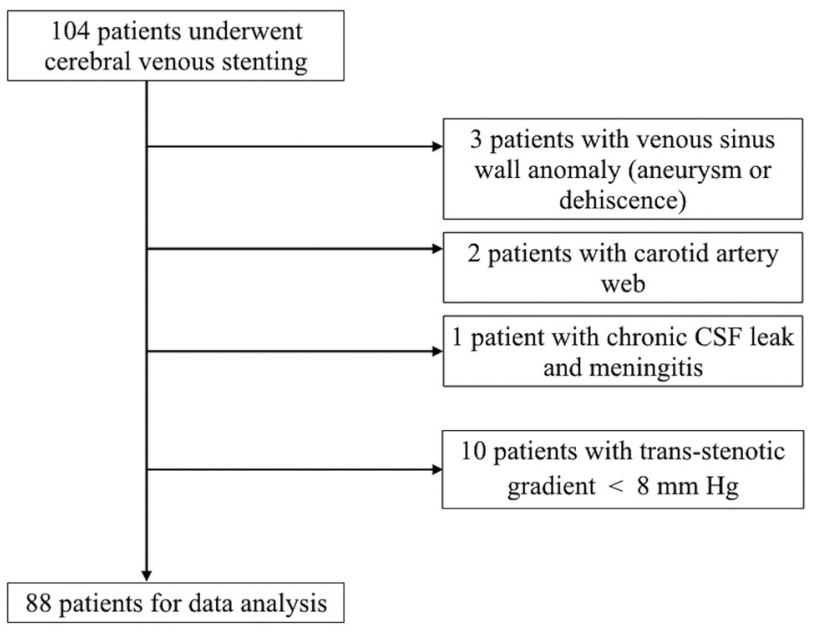

FIG 2. Study flow chart. statistically significant. The GH/SH and trans-stenotic gradients were compared between IPT and IIH groups using a MannWhitney 2-tailed test. The intraclass correlation coefficient was used to measure the interrater agreement for sellar volumes. An ANCOVA was used to test age, sex, the type of stenosis (intrinsic versus extrinsic), and BMI as potential confounding explanatory variables.

\section{RESULTS}

A total of 104 patients were screened between January 2012 and December 2017. Sixteen patients were excluded (see the flow chart in Fig 2). The median age of the 88 patients who underwent lateral sinus stent placement was 37 years (range, 20-75 years), and $94 \%$ were women. Patients' baseline characteristics are detailed in the Table. No significant difference in age or sex was noted among the 3 groups. The BMI did not differ between the 2 groups of patients with symptomatic sinus stenosis.

The mean sellar volume was $962 \pm 317 \mathrm{~mm}^{3}$ in the IPT group, $1079 \pm 455 \mathrm{~mm}^{3}$ in the IIH group, and $534 \pm 118 \mathrm{~mm}^{3}$ for the control group. Patients with IPT and IIH undergoing venous stent placement had significantly higher sellar volumes than the control group $(P<.001)$. There was no difference in the sellar volumes between IPT and IIH groups $(P=.63)$ (Fig 3). The intraclass correlation coefficient was 0.782 for sellar volumes between the independent reviewers.

The mean ratio of $\mathrm{GH} / \mathrm{SH}$ was $0.436 \pm 0.21$ for the IPT group and $0.375 \pm 0.18$ for the IIH group $(P=.25)$. There was a trend toward higher trans-stenotic gradients for the IIH group (mean, $11.3 \pm 6.1 \mathrm{~mm} \mathrm{Hg}$ ) compared with the IPT group (mean, $8.9 \pm$ $5.4 \mathrm{~mm} \mathrm{Hg})(P=.07)$, as depicted in Fig 4. The ANCOVA showed no association between sellar volumes or $\mathrm{GH} / \mathrm{SH}$ and age, sex, trans-stenotic gradients, BMI, or the type of venous stenosis.

\section{DISCUSSION}

In the current study, we found that the sellar volumes and heights were significantly higher in patients with symptomatic lateral sinus stenosis compared with a sample of control subjects. There was no significant difference in sellar volumes or $\mathrm{GH} / \mathrm{SH}$ between patients with IPT and IIH. These findings suggest that an empty sella is found in 2 differing groups of patients, both benefiting from venous sinus stent placement. To our knowledge, the sellar characteristics of patients with IPT, but not satisfying the Dandy criteria, have not previously been reported or compared with patients with elevated intracranial pressure and with control subjects. An empty or partially empty sella has been reported in patients with both IPT and no elevated intracranial pressure ${ }^{23}$ and patients with $\mathrm{IIH} .^{24}$ Patients with IIH can present with IPT, ${ }^{25}$ and venous sinus stenosis has been observed and treated in both instances. $^{26,27}$ However, an empty sella is less commonly observed in
Patients' baseline characteristics

\begin{tabular}{lcccc}
\hline & IPT & IIH & Control & $P$ Value \\
\hline No. & 34 & 54 & 39 & \\
Age (median in years) & $39 \pm 15$ & $35.5 \pm 113$ & $35 \pm 14$ & .65 \\
Women (No. and \%) & $32(94.1)$ & $51(94.4)$ & $36(92.3)$ & .91 \\
BMI (mean) & $27.7 \pm 5.3$ & $31.9 \pm 6.7$ & $\mathrm{~N} / \mathrm{A}$ & .06 \\
Pulsatile tinnitus (\%) & 100 & 53.7 & $\mathrm{~N} / \mathrm{A}$ & \\
$\begin{array}{l}\text { Lumbar puncture opening pressure } \\
\quad\left(\mathrm{cm} \mathrm{H} \mathrm{H}_{2} \mathrm{O} \text {, mean and range) }\right.\end{array}$ & $\mathrm{N} / \mathrm{A}$ & $31.8 \pm 10.6(21-53)$ & $\mathrm{N} / \mathrm{A}$ & \\
\hline
\end{tabular}

Note:-N/A indicates not available. 
other causes of chronic elevation of intracranial pressure or after venous thrombosis. ${ }^{28,29}$ Eisenman et $\mathrm{al}^{30}$ also observed a high rate of empty sella and transverse sinus stenosis in a series of 40 patients presenting with pulsatile tinnitus who underwent transtemporal surgical reconstruction of sigmoid sinus wall anomalies.

On the basis of our results, we suggest that the arachnoidocele of the sella is not the consequence of an elevation of the intracranial pressure but rather a consequence of a

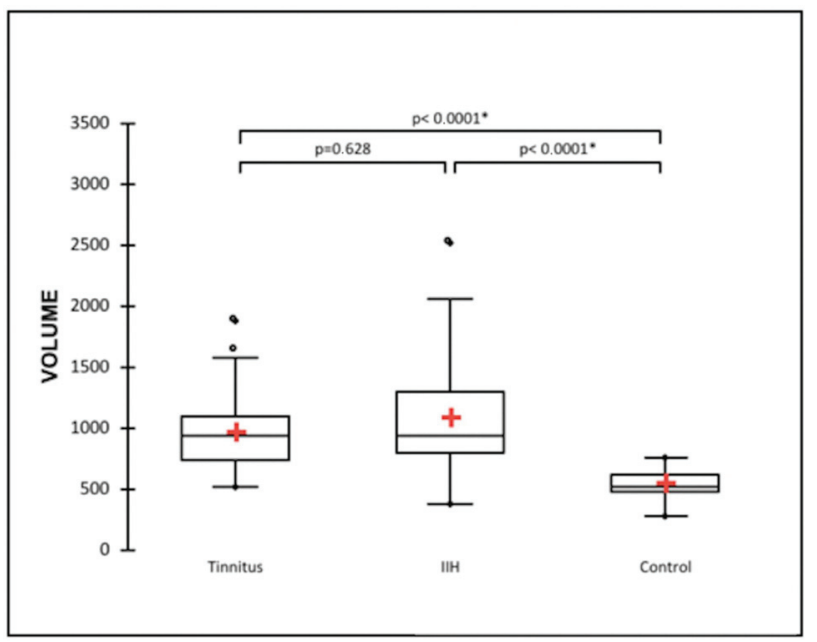

FIG 3. Estimated sellar volumes (cubic millimeters) based on preoperative CTA measurements for patients with isolated venous pulsatile tinnitus and idiopathic intracranial hypertension. disorder of CSF resorption following the elevation of venous pressure.

The potential mechanism of pulsatile tinnitus in the context of a cerebral venous sinus stenosis with a significant transstenotic gradient has been previously discussed. ${ }^{18,30}$ Flow turbulence secondary to acceleration through the stenosis, combined with the rhythmicity of the additional compression during the systole of venous structures in the vicinity of the inner ear, is hypothesized to explain the pulsatile nature of the tinnitus.

On the other hand, the physiopathology of IIH may be complex, and proposed mechanisms remain to be demonstrated. The default in CSF reabsorption at the arachnoid granulations of the superior sagittal sinus is increasingly being linked to an increased endoluminal pressure in the superior sagittal sinus in the context of hemodynamic stenosis. ${ }^{31}$

Various theories have been suggested to explain the physiopathology of the empty sella: congenital absence or insufficiency of the diaphragm sellae, induced enlargement of the bony sellar compartment, or necrosis of a previous pituitary adenoma. ${ }^{32-34}$ More recent work on animal models of CSF turnover pointed out the role of cervical lymphatics. ${ }^{35-37}$ CSF that is not reabsorbed through arachnoid granulations at the superior sagittal sinus may reach the cervical lymphatics by tracking along the cranial nerves ${ }^{38}$ or the Virchow-Robin spaces. ${ }^{39}$ Increased CSF spaces and infiltration of the sella may occur once these compensatory mechanisms are exceeded, and this may explain the radiologic findings in patients with venous sinus stenosis, including an empty sella syndrome.

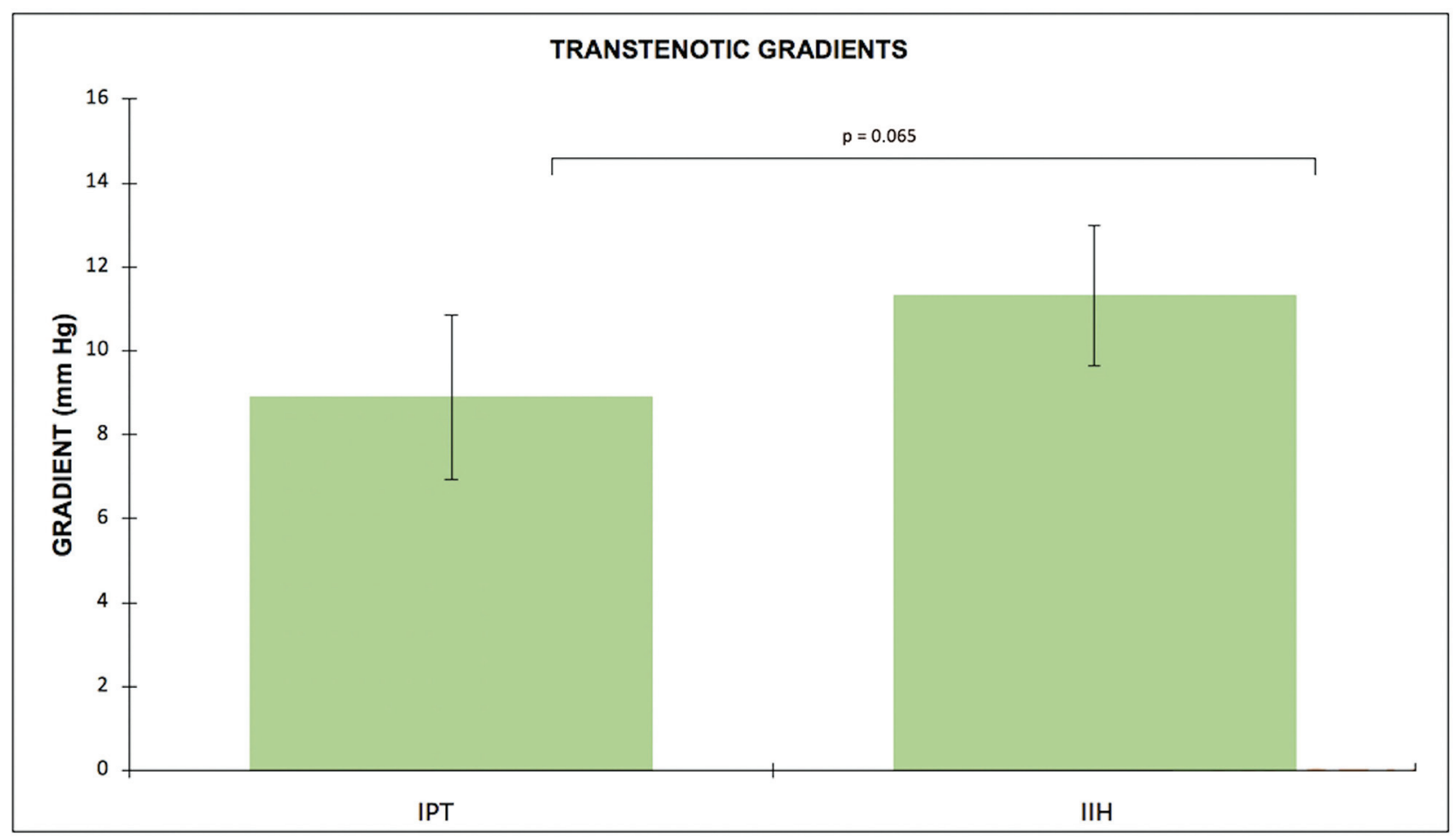

FIG 4. Trans-stenotic gradients (millimeters of mercury) based on local anesthesia venous manometry measurements for patients with isolated venous pulsatile tinnitus and $\mathrm{IIH}$. 
We propose that enlarged CSF spaces found in patients with either intracranial hypertension or pulsatile tinnitus are the consequence of a common mechanism-a hemodynamic venous sinus stenosis. The hemodynamic stenosis of the lateral sinuses would, therefore, be a pathologic entity in itself, leading to a disruption of the CSF drainage at the origin of specific radiologic signs of this entity, regardless of the intracranial pressure. We would propose a new name for this entity: "symptomatic lateral sinus stenosis." Levitt et $\mathrm{al}^{20}$ reported the results of 9 patients without IIH who underwent venous stent placement and grouped them under the terminology "symptomatic venous sinus stenosis." Demonstration of causality remains, however, beyond the scope of the current study.

The reason that some patients with lateral sinus stenosis go on to develop isolated IPT versus IIH remains unclear. We did not find a significant correlation among age, sex, and the type of sinus stenosis. In the current study, we observed a trend to indicate a graded clinical spectrum for symptomatic cerebral venous sinus stenosis. Our study was not primarily designed to and lacks the power to study explanatory variables for the difference between patients with IIH and IPT. Obesity, hormonal factors, brain volumes, associated venous sinus anomalies, and reversibility of the enlarged sella would be additional variables to explore in future research. We elected to exclude patients with associated sigmoid sinus wall anomalies in the current study because endovascular therapy can also be effective in dealing with this etiology of pulsatile tinnitus. ${ }^{19}$

One of the limitations of our study lies in its retrospective nature. Discrimination between patients with IIH and IPT relied on retrospective chart review and on chart annotation or lumbar puncture opening pressures, ophthalmologic assessments, and clinical histories. However, the main outcome was based on prospectively collected radiologic data by 2 independent reviewers. Because lumbar puncture is not part of our routine work-up for patients with IPT, it is possible that some patients in this group had an unrecognized intracranial hypertension. Lumbar puncture was performed in the first 2 patients with IPT considered for venous stent placement. Neither had headache, papilledema, nor sixth cranial nerve palsy. The opening pressures were, respectively, 14 and $16 \mathrm{~cm} \mathrm{H}_{2} \mathrm{O}$. Both patients developed a cerebral hypotension syndrome following the lumbar puncture and required a blood patch.

We considered, at that time, that submitting the IPT group to lumbar punctures strictly for academic purposes was unethical, though this choice limits interpretation of the current study. We have since restricted the lumbar punctures to the group of patients presenting with papilledema or otherwise suspected of having IIH. Future research should consider lumbar puncture in patients with IPT as long as the ethical aspects have been debated. Even though MR imaging with a sella turcica protocol would have provided a more accurate estimation of sellar volumes, we elected to use the CTA performed in our institution to help standardize the measurements. We did not repeat an MR imaging at our institution for patients who already had one in another center. Dedicated sella turcica sequences were, therefore, not available for all patients. This method may overestimate the volume of CSF in the sella turcica, but we were more interested in the relative value of sellar volumes among the 3 samples of subjects than the absolute value. Moreover, the intraclass coefficient was good between the 2 reviewers. The accuracy of volume estimation may also have been limited by the differing sellar shapes. Software calculation may be considered in future work. We did not look at the reversibility of the sinus stenosis after treatment. Controversy surrounding the cause-and-effect relationship of venous stenosis and elevated intracranial pressure ${ }^{40-43}$ should, nevertheless, be explored in future research.

\section{CONCLUSIONS}

The current study supports our hypothesis that sellar volumes are comparable in between patients treated for a symptomatic venous sinus stenosis and are larger than in a control group. We suggest that the empty sella is a radiologic sign of hemodynamic lateral sinus stenosis rather than elevated intracranial pressure. Various clinical presentations may thus be regrouped under a new clinical entity: the symptomatic lateral sinus stenosis. Future research should prospectively look at the long-term radiologic and clinical outcomes of untreated or asymptomatic patients with a lateral sinus stenosis. The concept of a clinical spectrum for symptomatic cerebral venous stenosis may be explored by studying factors that may differentiate IIH from IPT.

\section{REFERENCES}

1. Naing S, Frohman LA. The empty sella. Pediatr Endocrinol Rev 2007;4:335-42 Medline

2. Davis S, Tress B, King J. Primary empty sella syndrome and benign intracranial hypertension. Clin Exp Neurol 1978;15:248-57 Medline

3. Bidot S, Saindane AM, Peragallo JH, et al. Brain imaging in idiopathic intracranial hypertension. J Neuroophthalmology 2015;35: 400-11 CrossRef Medline

4. Agid R, Farb RI, Willinsky RA, et al. Idiopathic intracranial hypertension: The validity of cross-sectional neuroimaging signs. Neuroradiology 2006;48:521-27 CrossRef Medline

5. Brodsky MC, Vaphiades M. Magnetic resonance imaging in pseudotumor cerebri. Ophthalmology 1998;105:1686-93 CrossRef Medline

6. de Vries-Knoppert WA. Primary empty sella syndrome and benign intracranial hypertension. Doc Ophthalmol 1986;61:319-25 Medline

7. Foley KM, Posner JB. Does pseudotumor cerebri cause the empty sella syndrome? Neurology 1975;25:565-69 CrossRef Medline

8. Degnan AJ, Levy LM. Pseudotumor cerebri: brief review of clinical syndrome and imaging findings. AJNR Am J Neuroradiol 2011;32:1986-93 CrossRef Medline

9. Rohr AC, Riedel C, Fruehauf MC, et al. MR imaging findings in patients with secondary intracranial hypertension. AJNR Am J Neuroradiol 2011;32:1021-29 CrossRef Medline

10. Ahmed RM, Wilkinson M, Parker GD, et al. Transverse sinus stenting for idiopathic intracranial hypertension: a review of $\mathbf{5 2}$ patients and of model predictions. AJNR Am J Neuroradiol 2011;32:1408-14 CrossRef Medline

11. Higgins JNP, Owler BK, Cousins C, et al. Venous sinus stenting for refractory benign intracranial hypertension. Lancet 2002;359:22830 CrossRef Medline

12. Dinkin MJ, Patsalides A. Venous sinus stenting in idiopathic intracranial hypertension. J Neuroophthalmol 2017;37:113-21 CrossRef Medline

13. Sismanis A. Otologic manifestations of benign intracranial hypertension syndrome: diagnosis and management. Laryngoscope 1987;97:1-17 CrossRef Medline 
14. Reardon MA, Raghavan P. Venous abnormalities leading to tinnitus: imaging evaluation. Neuroimaging Clin N Am 2016;26:237-45 CrossRef Medline

15. Dong C, Zhao PF, Yang JG, et al. Incidence of vascular anomalies and variants associated with unilateral venous pulsatile tinnitus in 242 patients based on dual-phase contrast-enhanced computed tomography. Chin Med J (Engl) 2015;128:581-85 CrossRef Medline

16. Dietz RR, Davis WL, Harnsberger HR, et al. MR imaging and MR angiography in the evaluation of pulsatile tinnitus. AJNR Am J Neuroradiol 1994;15:879-89 Medline

17. Krishnan A, Mattox DE, Fountain AJ, et al. CT arteriography and venography in pulsatile tinnitus: preliminary results. AJNR Am J Neuroradiol 2006;27:1635-68 Medline

18. Lenck S, Labeyrie MA, Vallee F, et al. Stent placement for disabling pulsatile tinnitus caused by a lateral sinus stenosis: a retrospective study. Oper Neurosurg (Hagerstown) 2017;13:560-65 CrossRef Medline

19. Yang I-H, Pereira VM, Lenck S, et al. Endovascular treatment of debilitating tinnitus secondary to cerebral venous sinus abnormalities: a literature review and technical illustration. J Neurointerv Surg 2019;11:841-46 CrossRef Medline

20. Levitt MR, Albuquerque FC, Gross BA, et al. Venous sinus stenting in patients without idiopathic intracranial hypertension. $J$ Neurointerv Surg 2017;9:512-15 CrossRef Medline

21. Smith JL. Whence pseudotumor cerebri? J Clin Neuroophthalmol 1985;5:55-66 Medline

22. Lenck S, Vallée F, Labeyrie M-A, et al. Stenting of the lateral sinus in idiopathic intracranial hypertension according to the type of stenosis. Neurosurgery 2017;80:393-400 CrossRef Medline

23. Weissman JL, Hirsch BE. Imaging of tinnitus: a review. Radiology 2000;216:342-49 Medline

24. Silbergleit R, Junck L, Gebarski SS, et al. Idiopathic intracranial hypertension (pseudotumor cerebri): MR imaging. Radiology 1989;170:207-09 CrossRef Medline

25. Sismanis A, Butts FM, Hughes GB. Objective tinnitus in benign intracranial hypertension: an update. Laryngoscope 1990;100:33-36 CrossRef Medline

26. Bracard S, Schmitt E, Klein O, et al. "Benign” intracranial hypertension: neuroradiology and endovascular treatments (in French). Neurochirurgie 2008;54:721-73 CrossRef Medline

27. Puffer RC, Mustafa W, Lanzino G. Venous sinus stenting for idiopathic intracranial hypertension: a review of the literature. $J$ Neurointerv Surg 2013;5:483-86 CrossRef Medline

28. Kesavadas C, Thomas B, Kapilamoorthy T, et al. Imaging signs in idiopathic intracranial hypertension: are these signs seen in secondary intracranial hypertension too? Ann Indian Acad Neurol 2013;16:229 CrossRef Medline
29. Ridha MA, Saindane AM, Bruce BB, et al. Magnetic resonance imaging findings of elevated intracranial pressure in cerebral venous thrombosis versus idiopathic intracranial hypertension with transverse sinus stenosis. Neuroophthalmology 2013;37:1-6 CrossRef Medline

30. Eisenman DJ, Raghavan P, Hertzano R, et al. Evaluation and treatment of pulsatile tinnitus associated with sigmoid sinus wall anomalies. Laryngoscope 2018;128:S1-13 CrossRef Medline

31. Markey KA, Mollan SP, Jensen RH, et al. Understanding idiopathic intracranial hypertension: mechanisms, management, and future directions. Lancet Neurol 2016;15:78-91 CrossRef Medline

32. Weisberg LA, Housepian EM, Saur DP. Empty sella syndrome as complication of benign intracranial hypertension. J Neurosurg 1975;43:177-80 CrossRef Medline

33. Kyung SE, Botelho JV, Horton JC. Enlargement of the sella turcica in pseudotumor cerebri. J Neurosurg 2014;120:538-42 CrossRef Medline

34. Bjerre P. The empty sella: a reappraisal of etiology and pathogenesis. Acta Neurol Scand, Suppl 1990;130:1-25 Medline

35. Johnston M, Zakharov A, Papaiconomou C, et al. Evidence of connections between cerebrospinal fluid and nasal lymphatic vessels in humans, non-human primates and other mammalian species. Cerebrospinal Fluid Res 2004;1:2 CrossRef Medline

36. Brinker T, Stopa E, Morrison J, et al. A new look at cerebrospina fluid circulation. Fluids Barriers CNS 2014;11:10 CrossRef Medline

37. Bulat M, Klarica M. Recent insights into a new hydrodynamics of the cerebrospinal fluid. Brain Res Rev 2011;65:99-112 CrossRef Medline

38. McComb JG. Recent research into the nature of cerebrospinal fluid formation and absorption. J Neurosurg 1983;59:369-83 CrossRef Medline

39. Cherian I, Beltran M, Kasper E, et al. Exploring the Virchow-Robin spaces function: a unified theory of brain diseases. Surg Neurol Int 2016;7(Suppl 26):S711-14 CrossRef Medline

40. Bateman GA. Stenoses in idiopathic intracranial hypertension: to stent or not to stent? AJNR Am J Neuroradiol 2008;29:215 CrossRef Medline

41. Fraser JA, Leung AE. Reversibility of MRI features of pseudotumor cerebri syndrome. Can J Neurol Sci 2014;41:530-32 Medline

42. Rohr A, Dörner L, Stingele R, et al. Reversibility of venous sinus obstruction in idiopathic intracranial hypertension. AJNR Am J Neuroradiol 2007;28:656-59 Medline

43. De Simone R, Ranieri A, Montella S, et al. The role of dural sinus stenosis in idiopathic intracranial hypertension pathogenesis: the self-limiting venous collapse feedback-loop model. Panminerva Med 2014;56:201-09 Medline 